\title{
A 9-Week Nordic and Free Walking Improve Postural Balance in Parkinson's Disease
}

\section{(c) (i) (우 $\ominus$}

\author{
Authors \\ Leandro Tolfo Franzoni', Elren Passos Monteiro', Henrique Bianchi Oliveira', Rodrigo Gomes da Rosa', \\ Rochelle Rocha Costa ${ }^{1}$, Carlos Rieder ${ }^{2}$, Flávia Gomes Martinez ${ }^{1}$, Leonardo Alexandre Peyré-Tartaruga ${ }^{1}$
}

\author{
Affiliations \\ 1 Federal University of Rio Grande do Sul, Exercise \\ Research Laboratory, Porto Alegre, Brazil \\ 2 Hospital de Clinicas de Porto Alegre, Sleep and \\ Movement Disorders Clinics, Division of Neurology, \\ Porto Alegre, Brazil
}

Key words aerobic training, walking sticks, postural balance, Berg balance scale, locomotion

$\begin{array}{ll}\text { received } & 31.03 .2017 \\ \text { revised } & 22.11 .2017 \\ \text { accepted } & 29.11 .2017\end{array}$

Bibliography

DOI https://doi.org/10.1055/s-0043-124757

Sports Medicine International Open 2018; 2: E28-E34

(c) Georg Thieme Verlag KG Stuttgart · New York

ISSN 2367-1890

Correspondence

Prof. Leonardo Alexandre Peyré-Tartaruga

Federal University of Rio Grande do Sul

Exercise Research Laboratory

Rua Felizardo, 750
Porto Alegre, 90690200

Brazil

Tel.: + 55/513/3085 820, Fax: + 55/513/3085842

leonardo.tartaruga@ufrgs.br

\begin{abstract}
Aerobic training has a neuroprotective effect in people with Parkinson's disease. Recent evidence indicates that Nordic walking seems a promising alternative due to positive outcomes in functional mobility. However, the effects of Nordic walking compared to free walking on static and functional balance parameters are still unknown. The aim of this study was to evaluate the effects of nine weeks of Nordic and free walking training on static and functional balance. The sample size was 33 individuals with eight dropouts, leaving 25 individuals in the final sample (Nordic Walking, $n=14$, Free Walking, $n=11$ ). The participants underwent two evaluations in the present randomized clinical trial, pre- and post-training, to determine average velocity and root-mean-square values from center of pressure with eyes open and eyes closed. The functional balance showed approximately $5 \%$ improvement for the two groups $(p=0.04)$. The results indicate that nine weeks of Nordic and free walking training were enough to induce improvements in the proprioceptive system and functional balance.
\end{abstract}

\section{Introduction}

People with Parkinson's disease (PD) have an inadequate interaction among vestibular, visual and proprioceptive systems that are responsible for motor control $[13,30]$. Movement disorders are associated with impaired postural control in PD. Furthermore, the loss of dopaminergic neurons can provoke characteristic symptoms such as rigidity, bradykinesia and resting tremor [4]. These symptoms associated with the loss of postural control are detrimental to static and functional balance $[1,5,7]$.

Postural control is commonly evaluated by means of body stabilometry using the center of pressure (COP), average velocity (AV) and root mean square (RMS) as variables. Lower AV and higher RMS values in subjects with PD compared to healthy subjects can indi- cate an inability to control posture and as a result, the risk of falls can increase $[5,7]$. Moreover, balance can be evaluated clinically with the Berg Balance Scale (BBS). The final BBS score is clinically relevant; the higher the score, the better functional balance is. Therefore, strategies to improve the balance such as therapeutic interventions or physical exercise are important to persons with PD $[11,29]$. It has been well established that aerobic training is useful to patients with PD due to its neuroprotective effect [2, 22, 24]. Alberts et al. [2] showed that after an aerobic training program, the amount of dopamine was similar to the period "on" medication for PD. This can be explained by the increase in the brain-derived neurotrophic factor (BDNF), which is responsible for promoting neuroplasticity. 
Neuroplasticity can also be stimulated by motor practices that challenge the learning of a new technique. Nordic walking (NW, walking with poles) is a new training model that stimulates those with PD to leave automatism and generate new motor learning. Unlike free walking (FW, walking without poles), the use of poles provides more security and stability during gait due to the ground support. Furthermore, the use of the hands to grip the poles stimulates the mechanoreceptors, providing better integration between the systems of postural control.

Although the literature reports that NW promotes benefits such as an increase in functional mobility in patients with PD when compared with $\mathrm{FW}[8,18,27,29]$, there is a gap relative to the effects of NW training on static and functional balance. To our knowledge, there are no comparative studies between walking with and without poles that evaluated COP and BBS in PD individuals. Therefore, the aim of the present study was to evaluate the effects of 9 weeks of NW and FW training on COP parameters and BBS. We hypothesized that the use of poles would promote improvements in the COP parameters and BBS when compared with walking without poles (i. e., free walking, FW) [18].

\section{Materials and Methods}

\section{Study design}

This study is a randomized clinical trial, in which participants, after signing the informed consent form, were randomly divided into two groups: NW and FW ( Fig. 1). The tool available at http:// www.randomization.org was used for randomization.

This research was conducted at the Exercise Research Laboratory (LAPEX) in the Universidade Federal do Rio Grande do Sul (UFRGS), with approval of the Ethics and Research Committee (CEP) of the Porto Alegre Clinical Hospital (HCPA) with register number (555 123). This study used a single blinded evaluator. We conducted our research according to the ethical standards of the International Journal of Sports Medicine [14].

\section{Subjects}

The patients were recruited randomly and on a voluntary basis from the Neurology Service of the HCPA and Parkinson's Association of Rio Grande do Sul, in Porto Alegre, RS, Brazil. The diagnosis of Parkinson's disease in the individuals participating in the study was rendered by neurologists using the criteria of the London Brain Bank (CBCL). After initial contact by telephone (from May 2013 to May 2014), the patients were invited to participate in the study and scheduled for evaluation. The eligibility of the subjects included: 1) a diagnosis of idiopathic Parkinson's disease; 2 ) regular medical treatment with drugs for PD; 3 ) aged over 50 years; 4) between stages 1-4 on the Hoehn and Yahr scale; 5) cognitive ability to follow the instructions of the study (MoCA $\geq 26$ score) [26]; 5) independent gait capacity; 6) no deep brain stimulation; 7) no associated ischemic or hemorrhagic stroke or other neurological disease; and 8) no training program or regular exercise within the last six months before the study.

The sample consisted of 33 volunteers aged over 50 years, 20 men and 13 women, with a clinical diagnosis of idiopathic PD and between stages 1-4 on the Hoehn and Yahr Scale. The subjects met all eligibility criteria, which included regular medical treatment with drugs for PD, the ability to comprehend the verbal instructions to do all trials and follow the training program, and no regular exercise in the last six months before the study.

\section{Randomization procedures}

Each subject received a code based on interview order. After anamnesis, the codes were transferred to a researcher not involved in any assessment stage or treatment session who was responsible for blind and random allocation of the volunteers (online by randomization.org) into two groups, NW and FW. After the randomization process, the researcher shared the assignment results only with the coordinating researcher. Volunteers were not permitted to switch intervention groups once assigned. Experimental procedures started thereafter.

\section{Training program}

A three-week control period was established for familiarizing the subjects with NW and FW. Both groups followed the training program for six weeks.

The training session was divided into three stages: a) stretching, joint mobility, and warm-up; b) main part (NW or FW); c) return to calm and stretching. Both the initial and final stretching sessions lasted five minutes and were standardized for both groups. The NW and FW subjects trained over nine weeks consisting of a periodized macrocycle divided into four mesocycles of three microcycles each. After three consecutive progressions, each group performed a regenerative section [18]. For more details on the nine-week training progression, see Monteiro et al. [18].

The participants were prescribed individualized training based on the maximal distance test (adapted by mile test). To evaluate the maximal distance, each subject was instructed to walk a total distance of 1600 meters. Subjects who could not complete the maximal distance due to fatigue could request the test be ended. The tests were individually timed and recorded along the distances covered. The individual distance of each patient was used to calculate the total training volume. A heart rate monitor, Model FT4 (Polar Electro Oy, Kempele, Finland), attached to the xiphoid process was used to control the progression of intensity for the training cycles, which ranged from 60 to $80 \%$ of maximal heart rate. To estimate maximal heart rate, we used the Tanaka equation (maximal heart rate $=208-0.7 x$ age) [26]. Additionally, we used the Borg RPE scale only to control training intensity, which ranged between 13 and 17. All participants were well familiarized with the Borg scale.

\section{Data collection and analysis}

\section{COP parameters}

Outcome assessments were performed at two different times (T1 - pre-training and, $\mathrm{T} 2$ - post-training). Tests were performed on three different days separated by about $48-72 \mathrm{~h}$, and all evaluators were blinded. First, a physiotherapist evaluated motor symptoms (Unified Parkinson's Disease Rating Scale - Part III), level of disease (Hoehn \& Yahr Scale) and functional balance (Berg Balance Scale). We performed anthropometric measurements on the second visit, followed by familiarization on a $60 \times 40 \mathrm{~cm}$ force platform (BP400600-1000, AMTI, Watertown, Massachusetts, USA). On the 


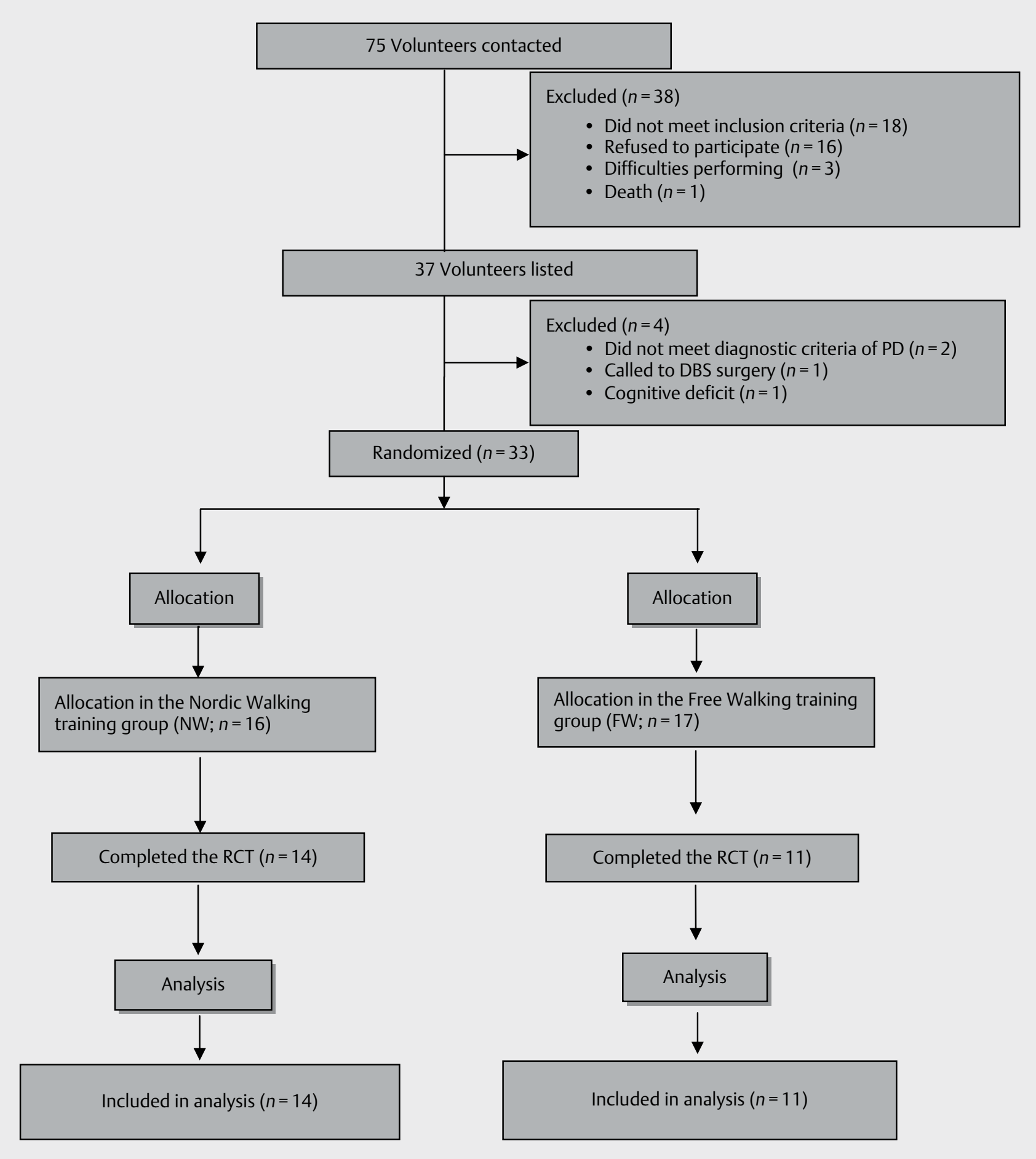

- Fig. 1 Flowchart of selection process and inclusion of volunteers. PD= Parkinson's disease; DBS= deep brain stimulation; RCT= randomized clinical trial.

third visit, the individuals performed stabilometric tests using the force platform. The parameters from COP used in the present study were the average velocity (AV), root mean square (RMS) and average displacement amplitude (ADA). The RMS and ADA were calculated for the anteroposterior and mediolateral axes [25]. In all evaluations, the subjects were in the "on" period of medication, taken up to $3 \mathrm{~h}$ before. Participants were instructed to notify the researcher of any change in medication during the training period.

Each test lasted $30 \mathrm{~s}$, and was performed three times in two conditions: eyes open and eyes closed. The subjects stood barefoot, with arms at their sides and feet together with heels aligned. In the condition with eyes open, the subjects were instructed to look at 
- Table 1 Characterization of participants with mean values (95\% confidence interval) for NW and FW groups.

\begin{tabular}{|l|c|c|c|}
\hline Variable & NW=14 & FW=11 & p-value \\
\hline Height $(\mathbf{m})$ & $1.68(1.64$ to 1.72$)$ & $1.59(1.55$ to 1.63$)$ & 0.003 \\
\hline Body mass $\mathbf{( k g )}$ & $81.71(73.28$ to 90.14$)$ & $64.75(57.13$ to 72.37$)$ & 0.004 \\
\hline Age (years) & $64.43(58.57$ to 70.28$)$ & $23.09(66.88$ to 75.30$)$ & 0.069 \\
\hline UPDRS III & $15.78(7.62$ to 23.94$)$ & $2.04(1.30$ to 2.78$)$ & 0.262 \\
\hline Hoehn \& Yahr & $1.60(1.22$ to 1.98$)$ & & 0.229 \\
\hline NW= Nordic walking; FW = free walking; UPDRS= Unified Parkinson's Disease Rating Scale. \\
\hline
\end{tabular}

a central fixation point. During the interval between tests ( $1 \mathrm{~min}$ ), subjects were seated. The order of conditions was randomized.

\section{Data analysis}

The COP signal was acquired at $A=\pi r^{2}$, frequency of $1000 \mathrm{~Hz}$ by the Nexus software (Vicon, Los Angeles, CA, USA). This program calculated the signals of COPx (anteroposterior) and COPy (mediolateral) according to the standard formulas:

$\operatorname{COPx}=-\frac{\mathrm{My}}{\mathrm{Fz}}$

where COPx represents anteroposterior displacement, My represents the moment or torque in the anteroposterior axis, and Fz represents the vertical force.

$\mathrm{COPy}=-\frac{\mathrm{Mx}}{\mathrm{Fz}}$

where COPy represents mediolateral displacement, Mx represents the moment or torque in the mediolateral axis, and Fz represents the vertical force.

Furthermore, we applied a fourth-order low-pass Butterworth filter of $10 \mathrm{~Hz}$. The AV, RMS, ADA were determined by algorithms constructed in the LabVIEW software (v. 8.5, National Instruments, Austin, TX, USA). The initial and final five seconds of the COP signal were cancelled. Therefore, we analyzed 20 s of the anteroposterior and mediolateral COP signal. An independent evaluator performed all analysis procedures.

\section{Functional balance}

Functional balance was evaluated using the BBS validated for Brazil and persons with PD [25]. The BBS has been used as the main instrument to evaluate balance in different populations. This scale contains 14 items that involve functional tasks on different bases of support, with five options that receive a score of 0 (unable to perform) to 4 (normal performance), according to participant performance. The total score range is 0 to 56 and higher scores represent better balance. Scores of 0 to 20 indicate that individuals are restricted to a wheelchair, 21 to 40 points indicate that individuals need assistance during gait, and 41 to 56 points indicate independence. Some studies showed strong internal consistency and inter- and intra-rater reliability in neurological diseases, such as stroke and PD [25]. The BBS validated for individuals with PD is a sensitive instrument that detects balance changes in this specific population [25].

\section{Statistical procedures}

Data are presented in descriptive measurements, using means and a $95 \%$ confidence interval for continuous measures. The description of the sample data at baseline was compared using a Student's t-test. Outcomes were analyzed via generalized estimating equations (GEE); testing the main effects of group (NW vs. FW), time (T1 vs. T2), and condition (eyes open vs. eyes closed); as well as respective interaction effects. The post hoc comparisons were done using the Bonferroni correction. Furthermore, the effect size (Cohen's d) was calculated from the difference in post-training values between the NW and FW groups, and classified as small (between 0.2 and 0.5 ), moderate (between 0.5 and 0.8 ), or large ( 0.8 or more) [6]. Data were analyzed using the Statistical Package for Social Sciences (SPSS) software, v.20.0, and the p-value adopted was set at 0.05 .

We calculated the sample size in the present study based on data from Kara et al. [16]. That study determined the average AV of the COPs. Furthermore, the selected study shows methodological similarities with our present study. The software used in our study was GPOWER version 3.1 (Power as 1-beta error probability: $95 \%$; effect size: 0.61; error assumed as alpha: 0.05 ). After calculation, 12 subjects were indicated for allocation equally into each group, 6 subjects in the NW group and 6 in the FW group. We decided to add more subjects to each group in case of drop-outs. Therefore, the present study was initiated with 33 patients divided randomly between the NW $(n=16)$ and FW $(n=17)$ groups.

\section{Results}

Four participants did not conclude the nine-week intervention period due to surgery, personal problems or reasons not reported (NW $=2$ and $F W=2$ ), representing a $12 \%$ drop-out rate. In addition, four participants did not complete the evaluations after the training program. Therefore, 29 participants finished the training sessions and 25 performed all evaluations after the training program ( Fig. 1). All participants had a frequency above $90 \%$, demonstrating adherence to training. Sample baseline characteristics are presented in $>$ Table 1.

The BBS score did not show any difference between the groups $(p=0.15)$ for all times evaluated. However, both groups showed improvements from $\mathrm{T} 1$ to $\mathrm{T} 2(\mathrm{p}=0.04)$ without significant interaction $(p=0.61)$, in the NW group from $51.50(95 \% \mathrm{Cl} 48.99$ to 54.01$)$ to 53.79 ( $95 \% \mathrm{Cl} 52.12$ to 55.46) and in the FW group from 47.09 (95\% $\mathrm{Cl} 40.17$ to 54.02 ) to 50.91 ( $95 \% \mathrm{Cl} 47.59$ to 54.23 ). Static balance was analyzed through AV, anteroposterior RMS, mediolateral RMS, anteroposterior ADA and mediolateral ADA with eyes open and eyes 
- Table 2 Mean (95\% confidence interval) values from center of pressure parameters.

\begin{tabular}{|c|c|c|c|c|c|}
\hline \multirow{3}{*}{ Variable } & \multirow{3}{*}{ Group } & \multicolumn{2}{|c|}{ Eyes closed } & \multicolumn{2}{|c|}{ Eyes open } \\
\hline & & T1 & $\mathrm{T} 2$ & T1 & $\mathrm{T} 2$ \\
\hline & & Mean \pm SE & Mean \pm SE & Mean \pm SE & Mean \pm SE \\
\hline \multirow[t]{2}{*}{$\mathrm{AV}\left(\mathrm{mm} \cdot \mathrm{s}^{-1}\right)$} & FW & 27.12 (20.25 to 33.99$)$ & 39.48 (27.13 to 51.83$)$ & 19.56 (15.18 to 23.93$)$ & 35.41 (26.51 to 44.32$)$ \\
\hline & NW & 38.48 (25.47 to 51.49$)$ & 48.29 (31.56 to 65.01$)$ & 26.64 (16.65 to 32.63$)$ & 31.78 (20.67 to 42.90$)$ \\
\hline \multirow[t]{2}{*}{ RMS AP (mm) } & FW & $7.15(5.82 \text { to } 8.47)^{\mathrm{a}, \mathrm{A}}$ & $11.75(8.56 \text { to } 14.93)^{\mathrm{a}, \mathrm{B}}$ & $6.54(4.80 \text { to } 8.27)^{\mathrm{a}, \mathrm{A}}$ & $10.47(7.79 \text { to } 13.14)^{\mathrm{a}, \mathrm{B}}$ \\
\hline & NW & $8.31(6.49 \text { to } 10.12)^{\mathrm{a}, \mathrm{A}}$ & $14.94(11.78 \text { to } 18.09)^{\mathrm{a}, \mathrm{B}}$ & $7.34(5.32 \text { to } 9.34)^{\mathrm{a}, \mathrm{A}}$ & $13.25(10.97 \text { to } 15.53)^{\mathrm{a}, \mathrm{B}}$ \\
\hline \multirow[t]{2}{*}{ RMS ML (mm) } & FW & $6.50(4.34 \text { to } 8.65)^{\mathrm{a}, \mathrm{A}}$ & $10.79(8.07 \text { to } 13.51)^{\mathrm{a}, \mathrm{B}}$ & $5.52(4.21 \text { to } 6.83)^{\mathrm{a}, \mathrm{A}}$ & 9.91 (7.19 to 12.62$)^{\mathrm{a}, \mathrm{B}}$ \\
\hline & NW & $7.47(6.27 \text { to } 8.67)^{\mathrm{a}, \mathrm{A}}$ & $10.74(7.58 \text { to } 13.89)^{\mathrm{a}, \mathrm{B}}$ & $6.15(4.88 \text { to } 7.42)^{\mathrm{a}, \mathrm{A}}$ & 8.35 (6.13 to 10.57$)^{\mathrm{a}, \mathrm{B}}$ \\
\hline \multirow[t]{2}{*}{ ADA AP (mm) } & FW & $38.24(30.11 \text { to } 46.38)^{\mathrm{a}, \mathrm{A}}$ & $57.93(41.48 \text { to } 74.38)^{\mathrm{a}, \mathrm{B}}$ & $32.46(24.61 \text { to } 40.31)^{\mathrm{a}, \mathrm{A}}$ & $56.12(38.93 \text { to } 73.31)^{a, b}$ \\
\hline & NW & $41.81(33.75 \text { to } 49.86)^{\mathrm{a}, \mathrm{A}}$ & $73.57(55.90 \text { to } 91.24)^{\mathrm{a}, \mathrm{B}}$ & $34.55(26.62 \text { to } 42.48)^{\mathrm{a}, \mathrm{A}}$ & $63.03(53.31 \text { to } 72.75)^{\mathrm{a}, \mathrm{B}}$ \\
\hline \multirow[t]{2}{*}{ ADA ML (mm) } & FW & $32.53(24.16 \text { to } 40.90)^{\mathrm{a}, \mathrm{A}}$ & $47.47(35.20 \text { to } 59.75)^{\mathrm{a}, \mathrm{B}}$ & $25.52(20.62 \text { to } 30.41)^{\mathrm{a}, \mathrm{A}}$ & $47.46(36.27 \text { to } 58.66)^{a, B}$ \\
\hline & NW & $37.69(30.91 \text { to } 44.46)^{\mathrm{a}, \mathrm{A}}$ & $48.65(30.89 \text { to } 66.40)^{\mathrm{a}, \mathrm{B}}$ & $34.25(23.35 \text { to } 45.15)^{\mathrm{a}, \mathrm{A}}$ & $41.77(30.74 \text { to } 52.80)^{a, b}$ \\
\hline
\end{tabular}

- Table 3 Main effects for Group (NW vs. FW), Time (T1 vs. T2), and Condition (eyes open vs. eyes closed), and interaction effects for the parameters from center of pressure.

\begin{tabular}{|l|c|c|c|c|c|c|c|}
\hline Variable & Group & Time & Condition & $\begin{array}{c}\text { Group }{ }^{*} \\
\text { Time }\end{array}$ & $\begin{array}{c}\text { Group }{ }^{*} \\
\text { Condition }\end{array}$ & $\begin{array}{c}\text { Time }{ }^{*} \\
\text { Condition }\end{array}$ & Group ${ }^{*}$ Time ${ }^{*}$ Condition \\
\hline AV (mm.s $\left.{ }^{-1}\right)$ & 0.368 & 0.011 & $<0.001$ & 0.527 & 0.013 & 0.864 & 0.204 \\
\hline AP RMS (mm) & 0.155 & $<0.001$ & 0.043 & 0.157 & 0.733 & 0.352 & 0.980 \\
\hline ML RMS (mm) & 0.999 & $<0.001$ & 0.002 & 0.231 & 0.295 & 0.582 & 0.514 \\
\hline AP ADA (mm) & 0.323 & $<0.001$ & 0.026 & 0.292 & 0.371 & 0.937 & 0.409 \\
\hline ML ADA (mm) & 0.690 & $<0.001$ & 0.076 & 0.257 & 0.737 & 0.722 & 0.297 \\
\hline AV = average velocity; RMS = root mean square; AP = anteroposterior; ML = mediolateral; ADA = average displacement amplitude; FW= free walking; \\
NW = Nordic walking; T1 = pre-test; T2 = post-test. \\
\hline
\end{tabular}

closed. Both groups showed increases in AV ( $\triangleright$ Table 2$)$ for both conditions with eyes open and eyes closed after nine weeks of training $(p=<0.001)$. Both groups showed significant differences between T1 and T2 $(p=0.01)$. There was a significant interaction between group and time for the AV $(p=0.01)$.

Regardless of condition (eyes open or closed), the anteroposterior RMS and mediolateral RMS increased (T1 vs T2: $p<0.001$ for anteroposterior and mediolateral). The anteroposterior RMS and mediolateral RMS were greater with eyes closed compared with eyes open. As expected, the RMS values were higher in the anteroposterior axis compared with the mediolateral one. These variables showed no interaction for group * condition, group * time, time * condition or group * time * condition ( $>$ Table 3 ).

There was an increase in the anteroposterior ADA and mediolateral ADA values with eyes open and eyes closed from $T 1$ to $T 2$ in both groups $(p<0.001)$. However, there was no interaction for group * condition, group * time, time * condition or group * time * condition for the anteroposterior ADA and mediolateral ADA.

\section{Discussion}

The present study evaluated the effects of a 9-week NW and FW training program on static and functional balance in persons with PD. The training program for both groups had individualized intensity (percentage of maximal heart rate) and volume (distance). It also followed a macrocycle model in which both groups had a logical sequence of progression in intensity and volume [18]. The main finding of this present study is that both groups improved functional balance and AV of COP, demonstrating that NW is as effective as FW.

There are significant effects after the training period on the outcome of functional balance in the NW and FW groups ( $\triangleright$ Table 4). We hypothesized that NW training would promote greater benefits due the higher task complexity due to probable increased neural plasticity. The mechanical stimulus received by the hands and transmitted to the brain may generate a greater excitation of dopaminergic neurons localized in the basal ganglions [9]. This stimulus, in turn, could promote more activation in the cortical regions responsible for motor control. Our hypothesis was not confirmed, because both NW and FW groups showed improvements in functional balance. This outcome indicates a substantial clinical effect for PD. Cognitive dysfunctions may have mediated and interfered with learning the NW technique without promoting the expected additional benefits compared with FW training [18, 24, 28].

For the COP parameters, there was an increase of AV (with and without the blindfold) after the training program in both groups, which indicates improvements in proprioceptive response in the function of postural sway in static conditions [19]. Furthermore, individuals with disturbances of the basal ganglia show the highest values of $A \bigvee$ when compared with healthy subjects. This represents 
- Table 4 Mean values (95\% confidence interval) of functional balance for both groups.

\begin{tabular}{|c|c|c|c|c|c|c|}
\hline & & \multirow{2}{*}{$\mathrm{T1}$} & \multirow{2}{*}{$\mathrm{T} 2$} & \multicolumn{3}{|c|}{$P=$ value } \\
\hline & & & & Group & Time & Group * Time \\
\hline BBS & $\begin{array}{l}\text { NW } \\
\text { FW }\end{array}$ & $\begin{array}{l}51.50(48.99 \text { to } 54.01) \\
47.09(40.17 \text { to } 54.02)\end{array}$ & $\begin{array}{l}53.79(52.12 \text { to } 55.46) \\
50.91(47.59 \text { to } 54.23)\end{array}$ & 0.15 & $0.04^{*}$ & 0.61 \\
\hline
\end{tabular}

Note: * indicates statistically significant difference. Initial evaluation, baseline (T1); evaluation after training (T2).

the great effectiveness of the proprioceptive mechanism in those with $\mathrm{PD}$, which manifests in a failure in the integration of the vestibular system [10].

We observed major values for the AV to the condition of eyes closed compared with eyes open. The first seconds of activity with the eyes open stimulate the visual and proprioceptive canals more, whereas eyes closed excites the vestibular canal more. However, in response to maintain activities with eyes open and eyes closed, there vestibular and proprioceptive systems respectively contribute $[4,9,17,19,28]$. Nevertheless, PD had impairment in the vestibular system, which explains the higher values for the AV with eyes open versus eyes closed. Aerobic training promotes greater dopamine production in the basal ganglia and consequently expands motor function in the brain stem $[9,28]$.

We observed increased RMS and ADA values after the training program in both groups. This effect can indicate an improvement in the ability to maintain postural control during static upright posture $[12,30]$. In general, aerobic training promotes a greater neural plasticity, increasing the excitation in the motor cortex through dopamine production. Therefore, we expected that both groups would improve their capacity to maintain postural control after the training program [2]. However, we suggested that dose-response effect was not sufficient or specific enough to promote additional improvements in the postural control during the static stance [15]. Interestingly, functional balance was also ameliorated after a relatively short time, showing that the NW intervention had the same direction of effect on both functional/dynamic and static balance. These outcomes indicate that the additional improvement in functional mobility seen recently using poles in comparison to free walking [18] is not accompanied by changes in postural control. We infer that, collectively, the additional benefit from NW practice should be related mainly to a major action from the upper limbs [20,21].

The limitations of present study include the short time of the intervention and the lack of a control group. For further studies, we suggest a longer intervention program of more than 12 weeks with 3 sessions per week, including a placebo or control group, and maintaining a diary of physical activity. Still, we point out that these outcomes were presented based on a very controlled training program using individualized loads (intensity and volume parameters) and following the principles of physical training. Again, the major electromyographic activity [20] and mechanical work [21] from the arms in NW could have provided an advantage over free walking in individuals with PD. Nevertheless, further studies focusing on specific adaptations on upper limb movement, not just in acute responses, but in a chronic perspective, are necessary to answer the question.

The outcomes of the present study are important for clinical rehabilitation of PD because the improvements in the variables related to functional performance can reduce the risk of falls [3, 23].
Therefore, these findings are compatible with the concept that NW may increase postural balance in PD. In conclusion, NW and FW promote effective and similar adaptations in balance for PD. We can use both modalities to improve balance in a rehabilitation program for PD.

\section{Acknowledgements}

Acknowledgements We acknowledge financial support from LAPEX, CAPES, CNPq and FIPE-HCPA ( ${ }^{\circ}$ 140051). We are grateful to the Locomotion Group of the Federal University of Rio Grande do Sul for discussions and comments. L.A. Peyré-Tartaruga is an established investigator of the Brazilian Research Council (CNPq), Brasília, Brazil.

Conflict of Interest

The authors declare that they have no conflict of interest.

\section{References}

[1] Adkin AL, Bloem BR, Allum JH. Trunk sway measurements during stance and gait tasks in Parkinson's disease. Gait Posture 2005; 22: 240-249

[2] Alberts JL, Linder SM, Penko AL, Lowe M], Phillips M. It is not about the bike, it is about the pedaling: Forced exercise and Parkinson's disease. Exerc Sport Sci Rev 2011; 39: 177-186

[3] Allen NE, Sherrington C, Paul SS. Canning CG. Balance and falls in Parkinson's disease: A meta-analysis of the effect of exercise and motor training. Mov Dis 2011; 26: 1605-1615

[4] Bohnen NI, Cham R. Postural control, gait, and dopamine functions in Parkinsonian movement disorders. Clin Geriatr Med 2006; 22: 797-812

[5] Carpenter MG, Allum JH, Honegger F, Adkin AL, Bloem BR. Postural abnormalities to multidirectional stance perturbations in Parkinson's disease. J Neurol Neurosur Psychiatry 2004; 75: 1245-1254

[6] Cohen J. The Effect Size Index: d.In: Statistical Power Analysis for the Behavioral Sciences. 2nd ed.Mahwah, NJ: Lawrence Erlbaum Associates, Publishers; 1988: 284-288

[7] Dimitrova D, Horak FB, Nutt JG. Postural muscle responses to multidirectional translations in patients with Parkinson's disease. J Neurophysiol 2004; 91: 489-501

[8] Figard-Fabre H, Fabre N, Leonardi A, Schena F. Physiological and perceptual responses to Nordic walking in obese middle-aged women in comparison with the normal walk. Eur J Appl Physiol 2010; 108: 1141-1151

[9] Frazzitta G, Maestri R, Ghilardi MF, Riboldazzi G, Perini M, Bertotti G, Boveri N, Buttini S, Lombino FL, Uccellini D, Turla M, Pezzoli G, Comi C. Intensive rehabilitation increases BDNF serum levels in Parkinsonian patients: A randomized study. Neurorehabil Neural Repair 2014; 28: 163-168 
[10] Freitas SM, Prado JM, Duarte M. The use of a safety harness does not affect body sway during quiet standing. Clin Biomech 2005; 20 : 336-339

[11] Fritz B, Rombach S, Godau J, Berg D, Horstmann T, Grau S. The influence of Nordic Walking training on sit-to-stand transfer in Parkinson patients. Gait Posture 2011; 34: 234-238

[12] Geurts AC, Nienhuis B, Mulder TW. Intrasubject variability of selected force-platform parameters in the quantification of postural control. Arch Phys Med Rehab 1993; 74: 1144-1150

[13] Gibb WR. Neuropathology of Parkinson's disease and related syndromes. Neurol Clin 1992; 10: 361-376

[14] Harriss DJ, Atkinson G. Ethical standards in sport and exercise science research: 2016 update. Int J Sports Med 2015; 36: 1121-1124

[15] Hubble RP, Naughton GA, Silburn PA, Cole MH. Trunk muscle exercises as a means of improving postural stability in people with Parkinson's disease: A protocol for a randomised controlled trial. BMJ open 2014; 4: e006095

[16] Kara B, Genc A, Colakoglu BD, Cakmur R. The effect of supervised exercises on static and dynamic balance in Parkinson's disease patients. NeuroRehabilitation 2012; 30: 351-357

[17] Lefaivre SC, Almeida QJ. Can sensory attention focused exercise facilitate the utilization of proprioception for improved balance control in PD? Gait Posture 2015; 41: 630-633

[18] Monteiro EP, Franzoni LT, Cubillos DM, de Oliveira Fagundes A, Carvalho AR, Oliveira HB, Pantoja PD, Schuch FB, Rieder CR, Martinez FG, Peyré-Tartaruga LA. Effects of Nordic walking training on functional parameters in Parkinson's disease: A randomized controlled clinical trial. Scand J Med Sci Sports 2016; 27: 351-358

[19] Palmieri RM, Ingersoll CD, Stone MB, Krause BA. Center-of-pressure parameters used in the assessment of postural control. J Sport Rehab 2002; 11: 51-66

[20] Pellegrini B, Peyré-Tartaruga LA, Zoppirolli C, Bortolan L, Bacchi E, Figard-Fabre H, Schena F. Exploring muscle activation during Nordic walking: A comparison between conventional and uphill walking. PloS one 2015; 10: e0138906
[21] Pellegrini B, Peyré-Tartaruga LA, Zoppirolli C, Bortolan L, Savoldelli A, Minetti AE, Schena F. Mechanical energy patterns in Nordic walking: Comparisons with conventional walking. Gait Posture 2017; 51: 234-238

[22] Petzinger GM, Fisher BE, McEwen S, Beeler JA, Walsh JP, Jakowec MW. Exercise-enhanced neuroplasticity targeting motor and cognitive circuitry in Parkinson's disease. Lancet Neurol 2013; 12: 716-726

[23] Pickering RM, Grimbergen YA, Rigney U, Ashburn A, Mazibrada G, Wood B, Gray P, Kerr G, Bloem BR. A meta-analysis of six prospective studies of falling in Parkinson's disease. Mov Dis 2007; 22: 1892-1900

[24] Reuter I, Mehnert S, Leone P, Kaps M, Oechsner M, Engelhardt M. Effects of a flexibility and relaxation programme, walking, and Nordic walking on Parkinson's disease. J Aging Res 2011; 2011: 232473

[25] Scalzo PL, Nova IC, Perracini MR, Sacramento DR, Cardoso F, Ferraz HB, Teixeira AL. Validation of the Brazilian version of the Berg balance scale for patients with Parkinson's disease. Arquivos de neuro-psiquiatria 2009; 67: 831-835

[26] Tanaka H, Monahan KD, Seals DR. Age-predicted maximal heart rate revisited. J Am Coll Cardiol 2001; 37: 153-156

[27] Tschentscher M, Niederseer D, Niebauer J. Health benefits of Nordic walking: A systematic review. Am J Prev Med 2013; 44: 76-84

[28] Tuon T, Valvassori SS, Lopes-Borges ], Luciano T, Trom CB, Silva LA, Quevedo J, Souza CT, Lira FS, Pinho RA. Physical training exerts neuroprotective effects in the regulation of neurochemical factors in an animal model of Parkinson's disease. Neuroscience 2012; 227: 305-312

[29] van Eijkeren FJ, Reijmers RS, Kleinveld MJ, Minten A, Bruggen JP, Bloem BR. Nordic walking improves mobility in Parkinson's disease. Mov Dis 2008; 23: 2239-2243

[30] Wild LB, de Lima DB, Balardin JB, Rizzi L, Giacobbo BL, Oliveira HB, de Lima Argimon II, Peyré-Tartaruga LA, Rieder CR, Bromberg E. Characterization of cognitive and motor performance during dual-tasking in healthy older adults and patients with Parkinson's disease. J Neurol 2013; 260: 580-589 